\title{
Persistent Cardiovascular and Behavioral Nociceptive Responses to Subcutaneous Formalin Require Peripheral Nerve Input
}

\author{
Bradley K. Taylor, ${ }^{1,2}$ M. Alex Peterson, ${ }^{1,2}$ and Allan I. Basbaum ${ }^{1,2,3}$ \\ ${ }^{1}$ W. M. Keck Foundation Center for Integrative Neuroscience and Departments of ${ }^{2}$ Anatomy and ${ }^{3}$ Physiology, \\ University of California at San Francisco, San Francisco, California 94143
}

\begin{abstract}
Hindpaw injection of formalin produces acute (Phase 1) and persistent (Phase 2) nociceptive behaviors. This model has provided critical evidence supporting a contribution of central sensitization (hyperexcitability of spinal neurons) to the expression of persistent pain. Here, we evaluated the contribution of ongoing peripheral nerve inputs to Phase 2 pain responses.
\end{abstract}

In addition to pain behavior (flinching), we measured formalin-evoked increases in arterial pressure and heart rate; these cardiovascular responses were also biphasic in nature. The arterial pressure response correlated highly with behavior, and was dependent on formalin concentration $(0.625-5.0 \%)$, indicating that it was largely driven by noxious input. Lightly anesthetized (0.7\% halothane) rats exhibited robust increases in blood pressure in the absence of pain behavior, indicating cardiovascular responses did not reflect somatomotor-cardiovascular coupling. Animals obtained from Charles River exhibited slightly larger Phase 2 flinching and heart rate responses compared to those obtained from Bantin and Kingman, suggesting cardiovascular-related pain responses can vary with the source of animal.

We next evaluated the contribution of ongoing peripheral nerve activity to the expression of the Phase 2 pressor, tachycardia, and flinch responses. After Phase 1 subsided, but before Phase 2 began, we locally anesthetized the ipsilateral or contralateral (control) hindpaw with a hydrophilic lidocaine derivative, QX-314 (2\%). Intraplantar QX314 blocked Phase 2 pressor, tachycardia and behavioral responses only when injected into the paw that received formalin $(2.5 \%$ or $\mathbf{1 0 . 0 \% )}$. We conclude that persistent ongoing activity in peripheral afferent fibers during Phase 2 is required for the persistent pain evoked by formalin.

[Key words: central sensitization, formalin, pain, nociception, blood pressure, heart rate, halothane, QX-314, rat]

Considerable evidence indicates that central sensitization of spinal dorsal horn neurons, produced by tissue injury, contributes to hyperalgesia and allodynia (Woolf, 1983; Cook et al., 1987; Dahl and Kehlet, 1993; Woolf and Chong, 1993; Dray et al., 1994). For example, Woolf (1983) demonstrated that hindpaw

\footnotetext{
Received May 15, 1995; revised July 3, 1995; accepted July 20, 1995.

This research was supported by Grants NS21445 and DA 08377. B.K.T. was a postdoctoral fellow supported by Training Grant NS07265.

Correspondence should be addressed to Dr. Bradley K. Taylor, University of California at San Francisco, Department of Anatomy, Box 0452, San Francisco, CA 94143-0452.

Copyright $\odot 1995$ Society for Neuroscience $0270-6474 / 95 / 157575-10 \$ 05.00 / 0$
}

tissue injury decreases the threshold for evoking nociceptive reflexes of the contralateral side. Since local anesthetic injection of the injured hindpaw did not eliminate the changes in the contralateral paw, Woolf concluded that persistent peripheral input was not required to maintain the hyperalgesia.

Although the contribution of central sensitization mechanisms in the formalin test is unclear, several receptor-mediated events during Phase 1 may effect the expression of Phase 2 responses (Dickenson and Sullivan, 1987; Coderre et al., 1990). Hindpaw injection of formalin produces a biphasic pain response (Dubuisson and Dennis, 1977; Tjolsen el al., 1992); first Phase 1 behavior (5 min), then a quiescent period (10-15 min), and then Phase 2 behavior ( $30-40 \mathrm{~min}$ ). Electrophysiological studies of dorsal horn ncurons revealed a comparable biphasic pattern of activation (Dickenson and Sullivan, 1987a,b). The initial barrage of C-fiber input in Phase 1 may produce an NMDA- and substance P-mediated central sensitization of dorsal horn neurons that generates Phase 2. Consistent with this hypothesis, administration of local anesthetics (Coderre et al., 1990), opiates (Dickenson and Sullivan, 1987a), NMDA antagonists (Haley et al., 1990; Yamamoto and Yaksh, 1992; Coderre and Melzack, 1992), or Substance P antagonists (Murray et al., 1991; Yamamoto and Yaksh, 1991) prior to, but not after Phase 1, significantly reduced Phase 2 behavioral responses and/or dorsal horn neuronal activity.

On the other hand, there is ongoing peripheral nerve activity during Phase 2 (Puig and Sorkin, 1994). Moreover, local anesthetic injection of the formalin-injected paw, after Phase 1 but before Phase 2 , abolished the second phase of dorsal horn neuronal activity (Dickenson and Sullivan, 1987b). Although these data suggest that persistent input during Phase 2 is also important, a similar treatment only partially depressed Phase 2 behavioral responses (Coderre et al., 1990). At least two factors may explain this discrepancy. First, electrophysiological studies are performed under general anesthesia, which may alter central sensitization (Herrero and Headley, 1995). Second, behavioral scoring methods in the formalin test have inherent limitations, including observer subjectivity and the potential for interactions between competing behaviors (Wheeler-Aceto and Cowan, 1991; Tjolsen et al., 1992; Abbott et al., 1995). In the present study, we measured formalin-evoked increases in blood pressure, heart rate, and pain behavior (flinching, a relatively objective behavioral measure) in awake animals after local anesthetic block of the hindpaw with a quaternary lidocaine derivative, QX-314.

We report that hindpaw formalin injection produces biphasic cardiovascular responses that correlate with pain behavior, and 
Table 1. Resting mean arterial pressure and heart rate in various experimental groups

\begin{tabular}{|c|c|c|c|c|c|c|c|}
\hline \multirow[b]{2}{*}{ Group } & \multirow[b]{2}{*}{$\begin{array}{l}\% \\
\text { Formalin }\end{array}$} & \multirow[b]{2}{*}{$n$} & \multicolumn{2}{|c|}{ Mean arterial pressure } & \multirow[b]{2}{*}{$n$} & \multicolumn{2}{|l|}{ Heart rate } \\
\hline & & & $\begin{array}{l}\text { Pre- } \\
\text { restraint }{ }^{a} \\
\text { or pre- } \\
\text { pinch }^{b}\end{array}$ & Preformalin & & $\begin{array}{l}\text { Pre- } \\
\text { restraint }{ }^{a} \\
\text { or pre- } \\
\text { pinch }^{b}\end{array}$ & Preformalin \\
\hline Charles River & $2.5 \%$ & 12 & $98 \pm 2$ & $100 \pm 2$ & 11 & $372 \pm 8$ & $379 \pm 8$ \\
\hline Bantin \& Kingman & $2.5 \%$ & 12 & $103 \pm 2$ & $104 \pm 2$ & 12 & $391 \pm 8$ & $398 \pm 7$ \\
\hline Dose response & $0.325 \%$ & 6 & $97 \pm 3$ & $103 \pm 3$ & 5 & $381 \pm 10$ & $398 \pm 17$ \\
\hline \multirow[t]{4}{*}{ Curve for formalin } & $0.625 \%$ & 6 & $101 \pm 2$ & $98 \pm 2$ & 5 & $408 \pm 5$ & $390 \pm 7$ \\
\hline & $1.25 \%$ & 8 & $99 \pm 3$ & $100 \pm 2$ & 7 & $407 \pm 17$ & $399 \pm 8$ \\
\hline & $2.5 \%$ & 7 & $90 \pm 3$ & $94 \pm 3$ & 7 & $388 \pm 14$ & $383 \pm 9$ \\
\hline & $5.0 \%$ & 7 & $99 \pm 2$ & $102 \pm 3$ & 6 & $388 \pm 16$ & $400 \pm 13$ \\
\hline $0.7 \%$ Halothane & $5.0 \%$ & 4 & $87 \pm 4^{b}$ & $85 \pm 6^{b}$ & 3 & $429 \pm 6^{b}$ & $417 \pm 21^{b}$ \\
\hline $0.9 \%$ Halothane & $5.0 \%$ & 3 & $80 \pm 1^{b}$ & $78 \pm 2^{b}$ & 2 & $405 \pm 6^{b}$ & $382 \pm 12^{b}$ \\
\hline $1.3 \%$ Halothane & $5.0 \%$ & 3 & $85 \pm 3^{b}$ & $82 \pm 2^{h}$ & 3 & $370 \pm 8^{* b}$ & $363 \pm 5^{b}$ \\
\hline $2.1 \%$ Halothane & $5.0 \%$ & 3 & $67 \pm 4^{* b}$ & $69 \pm 5^{* b}$ & 3 & $337 \pm 6^{* b}$ & $420 \pm 25^{b}$ \\
\hline QX314-Contralateral & $2.5 \%$ & 8 & $101 \pm 3$ & $97 \pm 2$ & 7 & $383 \pm 6$ & $390 \pm 10$ \\
\hline QX314-Ipsilateral & $2.5 \%$ & 8 & $103 \pm 2$ & $103 \pm 2$ & 8 & $375 \pm 14$ & $363 \pm 11$ \\
\hline QX314-Contralateral & $10.0 \%$ & 8 & $99 \pm 3$ & $98 \pm 3$ & 7 & $366 \pm 6$ & $372 \pm 8$ \\
\hline QX314-Ipsilateral & $10.0 \%$ & 8 & $105 \pm 3$ & $107 \pm 4$ & 8 & $357 \pm 9$ & $363 \pm 9$ \\
\hline
\end{tabular}

Values represent group mean \pm SEM. $n$, Number of animals. QX314, A quarternary lidocaine derivative. "Ipsilateral" and "Contralateral" refer to the QX314-injected paw, relative to the formalin-injected hindpaw.

"Awake animals.

Anesthetized animals.

* Significantly (Tukey, $P<0.05$ ) different from the appropriate $0.7 \%$ halothane group.

that QX-314 completely eliminated the cardiovascular and behavioral changes associated with Phase 2 . We conclude that ongoing activity in peripheral nerves contributes to the persistent pain evoked by formalin. These results support the previous electrophysiological studies of Dickenson and Sullivan (1987b), but not the behavioral studies of Coderre et al (1990).

\section{Materials and Methods}

\section{Animals}

Male, albino, Sprague-Dawley rats, 270-330 gm, were obtained from Charles River Laboratories (Hollister, CA) and Bantin and Kingman, Inc. (Fremont, CA). Several days before surgery, we individually housed animals in standard clear plastic cages in a temperature-controlled room $\left(20 \pm 1^{\circ} \mathrm{C}\right)$ on a $12 \mathrm{hr} / 12 \mathrm{hr}$ light-dark cycle $(6 \mathrm{~A} . \mathrm{M}$. lights on), with food and water provided ad libitum. The IACUC of the University of California at San Francisco approved all protocols.

\section{Arterial catheterization}

We constructed arterial catheters by heat-fusing a $4.5 \mathrm{~cm}$ length of PE10 polyethylene tubing to a $14.5 \mathrm{~cm}$ length of PE-50 tubing. Under pentobarbital anesthesia (50-60 mg/kg), we isolated the left femoral artery by blunt dissection, with care taken not to injure the femoral vein or sciatic nerve. Next, we advanced the catheter, prefilled with 100 IU/

Table 2. Pearson product-moment correlation coefficients between behavior (flinching), mean arterial pressure (pressor), and heart rate (tachycardia) responses

\begin{tabular}{lll} 
& $\begin{array}{l}\text { Charles } \\
\text { River }\end{array}$ & $\begin{array}{l}\text { Bantin \& } \\
\text { Kingman }\end{array}$ \\
\hline Pressor vs tachycardia & $0.959^{* *}$ & $0.965^{* *}$ \\
Pressor vs behavior & $0.831^{* *}$ & $0.578^{*}$ \\
Tachycardia vs behavior & $0.675^{*}$ & 0.412
\end{tabular}

$* p<0.05$.

${ }^{* *} p<0.001$. $\mathrm{ml}$ heparin, proximally to the renal bifurcation of the abdominal aorta and secured it with 4-0 suture. We then tunneled the PE-50 end of the catheter under the skin, exteriorized it at the nape, and sutured it to the dorsal neck muscles (splenicus cervicus). After recovery from anesthesia, we returned animals to their cages and allowed them to recover for $3-5 \mathrm{~d}$ betore testing.

\section{Data collection}

A digital blood pressure analyzer (Micromed Inc., Louisville, KY) conditioned arterial pressure waveforms. These were then amplified by an ultra-low compliance pressure transducer (Kobe, Arvada, $\mathrm{CO}$ ), yielding mean arterial pressure and heart rate. We collected data points at $1 \mathrm{~min}$ intervals, each representing 5 seconds of processed information. A computer stored this raw data, averaged over a $5 \mathrm{sec}$ interval, at $1 \mathrm{~min}$ time points. Using spreadsheet software, we calculated baseline blood pressure and heart rate as the average of five time points taken immediately before each experimental procedure (restraint, pinch, saline injection, or formalin injection), and used these values to calculate the respective change in mean arterial pressure or heart rate.

\section{General protocol and statistics}

Since adaptation to the test environment decreases variability associated with formalin-evoked behavior (Tjolsen et al., 1992), we transferred each animal to the laboratory, in a bedded $10 \times 10 \times 10$ inch Plexiglas box with food and water provided ad libitum, at least $16 \mathrm{hr}$ before testing. After this acclimation period, we connected the animal's catheter to the pressure transducer with an $80 \mathrm{~cm}$ piccc of $\mathrm{PE}-50$ tubing filled with heparinized saline, and began cardiovascular recording at least 20 min later; this time period allows blood pressure and heart rate in the awake animal to reach resting state (Taylor et al, 1994). After this acclimation period, animals received (in the following order): $1 \mathrm{~min}$ of restraint; a subcutaneous injection of physiological saline into the left, plantar hindpaw (unless otherwise noted); and a subcutaneous injection of dilute formalin into the right hindpaw. To inject $50 \mathrm{ml}$ of saline or dilute formalin subcutaneously into the plantar surface of the hindpaw, one investigator restrained the animal while a second performed the injection. Blood pressure and heart rate were recorded for 60-70 min following formalin injection. The time interval between restraint and saline injection, or saline injection and formalin injection, was at least $20 \mathrm{~min}$. This approach minimized interstimulus differences 


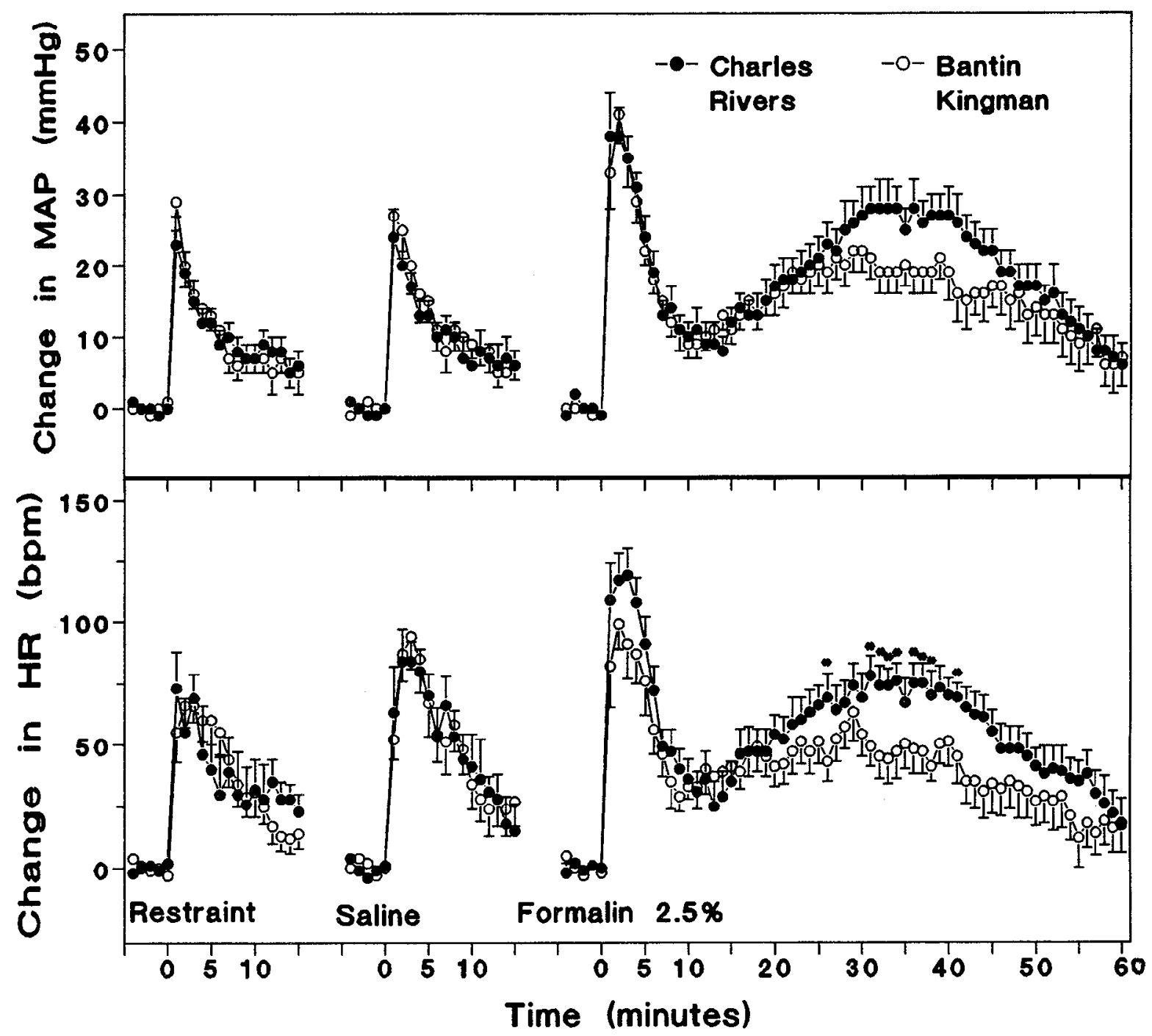

Figure 1. Vendor comparison of formalin-evoked cardiovascular responses. Sequential changes $\left({ }^{+}\right.$SEM) in mean arterial pressure (MAP, upper panel $)$ and heart rate $(H R$, lower panel $)$ following $1 \mathrm{~min}$ of restraint, restraint plus intraplantar saline injection $(50 \mathrm{ml})$, and restraint plus intraplantar formalin injection $(2.5 \%)$ in Sprague-Dawley rats obtained from either Charles River or Bantin and Kingman. *, Significantly $(p<0.05$ by posthoc $t$ (est) different from Bantin and Kingman group.

in resting blood pressure and hearl rate; 10 statistically evaluate this, we compared prehandling, presaline, and preformalin resting values using one-way ANOVA.

Each animal was used only once, that is, formalin injection was never repeated in the same animal. In rare cases, testing was not completed due to loss of catheter patency or unstable resting blood pressure and heart rate. Occasionally, methodological difficulties associated with measuring heart rate in conscious animals via an indwelling arterial catheter (i.e., poor pulse pressure, leakage or position-related artifacts) prevented analysis of heart rate (but rarely blood pressure) responses. The number of animals used in the statistical analysis is shown in Table 1.

To compare baseline arterial pressure or heart rate between groups, we used ANOVA (more than two groups) or an unpaired independent $t$ test (two groups). To compare either blood pressure or heart rate responses to restraint, saline, and formalin, we performed a mixed, repeated measures ANOVA on the first 10 min of poststimulus data points using Time (minutes) as the repeated measure and Stimulus as the other within-subjects factor. 'lo analyze only formalin-evoked responses, we performed a mixed, repeated measures ANOVA on all postformalin data using Time (minutes) as the repeated measure. Subsequent ANOVAs compared responses over minutes 1-10 (Phase 1) and minutes 25-55 (Phase 2). All values are expressed as mean SEM.

In selected experiments, we recorded formalin-evoked Phase 1 and/ or Phase 2 flinching behavior. We first counted the number of flinches during the second and third minute after injection. After a 5 min pause, we then counted flinches ovcr $2 \mathrm{~min}$ bins at $5 \mathrm{~min}$ intervals. These numbers were divided by two to yield flinches per minute. With this method, we were able to simultaneously record behavior in two animals at postformalin times $1-2,2-3,8-10,13-15 \ldots 68-70$ (in minutes). Data was analyzed with two-way, repeated measures ANOVA using Time as the within-subjects factor.

\section{Specific experimental protocols and statistics}

Vendor comparison experiment. Amimals purchased from Charles River $(n=12)$ and Bantin and Kingman $(n=12)$ were received on identical dates. One of each vendor was tested simultaneously using two blood pressure monitors. To reduce the stress associated with handling, animals were restrained for $1 \mathrm{~min}$ with the paw extended (as if to give an intraplantar injection) on the afternoon prior to experimentation. This procedure was repeated once. To evaluate correlations between the pressor, tachycardia, and flinching responses, we determined the Pearson product-moment correlation coefficients and associated probabilities between each response pair. Vendor (Charles River and Bantin and Kingman) was the between-subjects factor in the statistical analysis.

Formalin concentration dependence experiment. Animals were randomly assigned to one of five groups; each animal was tested with one dose of either $0.325 \%(n=6), 0.625 \%(n=6), 1.25 \%(n=8), 2.5 \%$ $(n=7)$, or $5.0 \%(n=7)$ formalin. Concentration (of formalin) was the between-subjects factor in the statistical analysis. 
Figure 2. Vendor comparison of formalin-evoked behavioral responses. Formalin-evoked flinches $( \pm$ SEM) in Sprague-Dawley rats obtained from either Charles River or Bantin and Kingman. *, Significantly $(p<0.05$ by post-hoc $t$ test) different from Bantin and Kingman group.

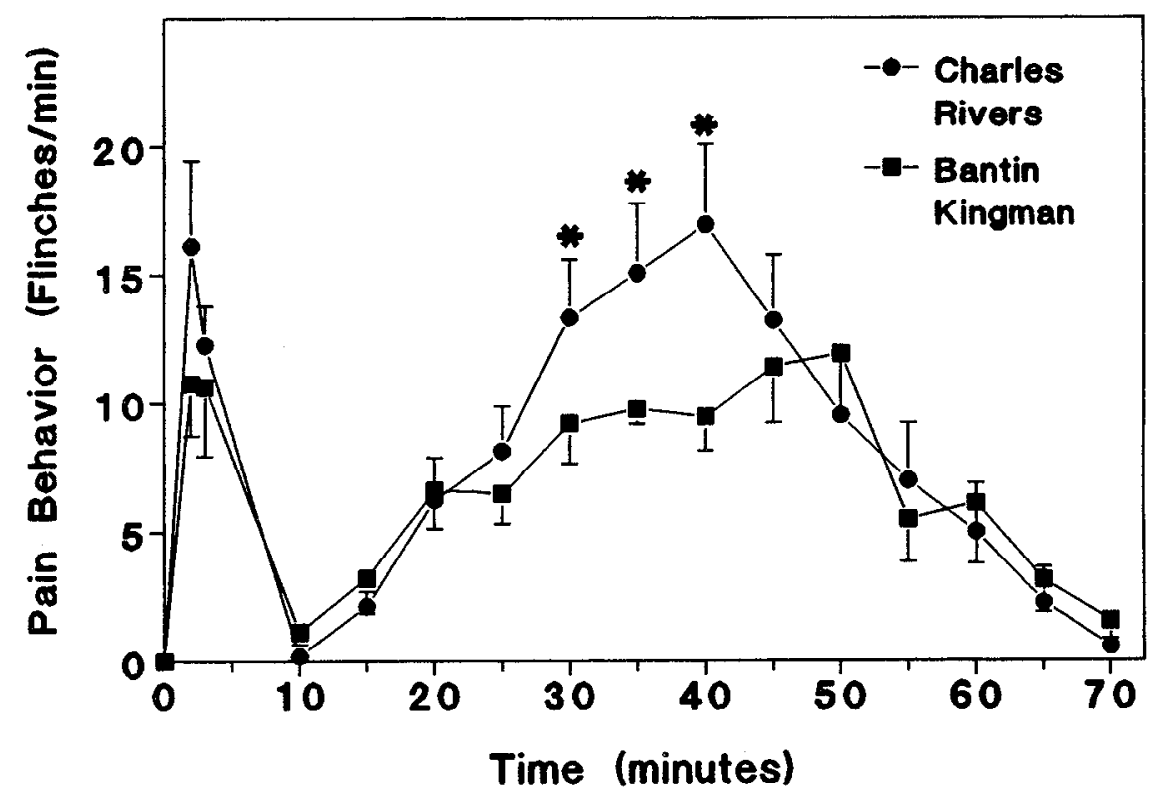

\section{Results}

Vendor comparison of formalin-evoked pain responses

Since rats obtained from different vendors display differences in descending catecholaminergic pathways (West et al., 1993) and in cardiovascular responses to sensory stimuli (Abdeen et al., 1995), we evaluated the stimulus-evoked response profiles in rats obtained from both Charles River and Bantin and Kingman. As shown in Table 1, we found no significant difference between the strains in baseline mean arterial pressure or baseline heart rate $(P>0.05)$.

To evaluate the relationship between the formalin-evoked behavioral and cardiovascular responses, we determined the correlation coefficients between them. As shown in Table 2 and Figures 1 and 2, animals from both vendors exhibited biphasic pressor and tachycardia that were highly correlated with each other. Furthermore, we found a significant correlation between the pressor and flinching responses in animals of either vendor. In contrast to Charles River animals, however, tachycardia and flinching responses were not significantly correlated in Bantin and Kingman animals.

To evaluate the contribution of restraint and needle insertion to formalin-evoked cardiovascular responses, we used a withinsubjects design to compare the effects of restraint, restraint plus intraplantar saline injection, and restraint plus intraplantar formalin injection. Table 1 illustrates that resting blood pressure or heart rate prior to restraint, saline, or formalin did not differ $(p$ $>0.05$ ). Figure 1 illustrates that restraint, saline, and formalin produced early increases in blood pressure and heart rate $(P<$ $0.001)$. ANOVA revealed a main effect of Stimulus over the first 10 post-formalin minutes of arterial pressure data in both Charles River and Bantin and Kingman animals $[F(2,14)=$ 14.7, $p<0.001$ and $\mathrm{F}(2,14)=5.0, p<0.05$ ], respectively); subsequent analysis showed that formalin produced greater Phase 1 pressor responses than did either restraint or saline injection (Fig. 1). Phase 1 pressor responses gradually declined to a minimum (interphase) at $12-13$ min postinjection. With respect to the heart rate data, ANOVA also revealed a main effect of Stimulus in the Charles River group $[F(2,12)=5.69, p<0.05]$ but not in the Bantin and Kingman group $(p>0.05)$ 


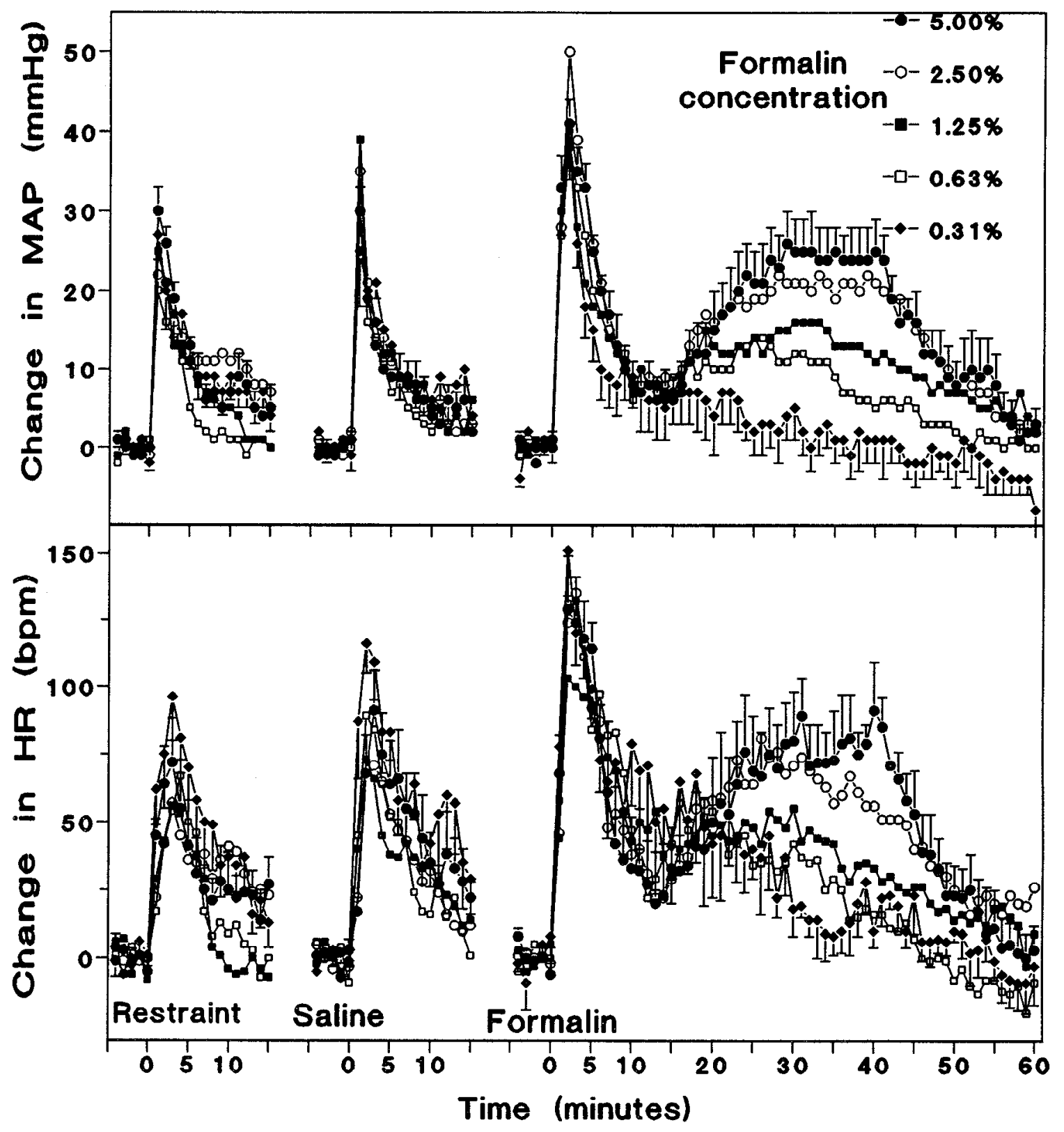

Figure 3. Formalin concentration dependence of cardiovascular responses. Sequential changes ( \pm SEM) in mean arterial pressure $(M A P$, upper panel) and heart rate (HR, lower panel) following one minute of restraint, restraint plus intraplantar saline injection (50 ml), and restraint plus intraplantar formalin injection $(0.31-5.0 \%)$.

Neither saline injection nor restraint alone produced significant changes in blood pressure or heart rate at these later time points. Although inspection of Figure 1 suggests that Phase 2 pressor responses were greater in Charles River as compared Bantin and Kingman rats, this did not reach statistical significance $(p>0.05)$. Since Charles River animals exhibited greater Phase 2 formalin-evoked tachycardia $[F(1,21)=4.48, p<0.05]$ and flinch $[F(1,14)=5.0, p<0.05]$ responses, compared to Bantin and Kingman animals (Figs. 1,2), we used the former in all subsequent studies.

\section{Formalin dose dependency of cardiovascular responses}

If cardiovascular responses are to be used to assess nociceptive processing, then they should increase with stimulus intensity, that is, formalin concentration (Coderre et al., 1993; Abbott et al., 1995). Table 1 shows that baseline mean arterial pressure and heart rate were not different among the formalin groups $(P$ $>0.05$ ). As in the previous experiment, control stimuli included restraint and saline injection; again, as shown in Figure 3, formalin evoked greater pressor $[F(2,62)=33.7, p<0.001]$ and tachycardia $[F(2,52)=28.5, p<0.001]$ responses. Subsequent analyses showed this to be true for the higher doses of formalin $(p<0.05)$, but not for the lowest $(0.325 \%)$ dose $(p>0.05)$. As observed with saline injection and restraint alone, the lowest concentration of formalin $(0.325 \%)$ did not produce significant increases in blood pressure and heart rate during these later timepoints. ANOVA did not yield any significant differences between the groups with respect to the early pressor or tachycardia responses evoked by handling, saline, or formalin $(P>0.05)$. On the other hand, we found a main effect of formalin concen- 


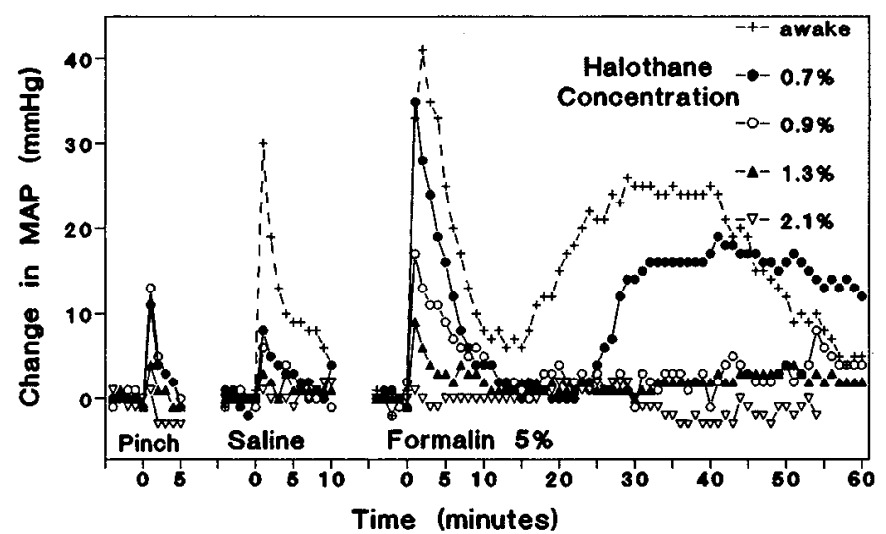

Figure 4. Halothane concentration dependence of pressor responses. Sequential changes in mean arterial pressure following tail pinch (1 $\mathrm{min})$, intraplantar saline injection $(50 \mathrm{ml})$, and intraplantar formalin injection $(5.0 \%)$ in animals anesthetized with halothane $(0.7-2.1 \%)$. For comparative purposes, the $5.0 \%$ formalin group from Figure 3 is shown.

tration on the magnitude of the Phase 2 pressor response $[F(4,29)=4.36, p<0.01]$. Although the magnitude of the tachycardia response appeared to increase with formalin concentration (Fig. 3), this did not reach statistical significance $[F(4,25)=2.48, p=0.07]$, possibly due to the high variability associated with this response.

\section{Effects of varying levels of halothane anesthesia on the pressor response}

Since concomitant formalin-evoked behaviors could contribute to autonomic changes (Sokolov, 1963; Cohen and Obrist, 1975; Hilton and Redfern, 1986; Taylor et al., 1994), we next measured formalin-induced cardiovascular responses in the absence of behavioral activity, that is, in lightly-anesthetized animals. Table 1 illustrates that prepinch baseline arterial pressure $[F(3,9)=7.0$, $p<0.01]$ and heart rate $[F(3,7)=42.2, p<0.001]$ were inversely proportional to halothane concentration, as were preformalin arterial pressure and heart rate $(p<0.05)$. As shown in Figure 4, animals under $0.7 \%$ halothane, termed lightly anesthetized animals, exhibited early pressor responses to pinch, saline injection, and 5\% formalin injection. For each of these treatments, the response peaked at $1 \mathrm{~min}$ after injection, then gradually declined to baseline levels within $10 \mathrm{~min}$. The formalinevoked Phase 1 response, however, was greater than that evoked by either pinch or saline: we found a main effect of Stimulus across the first five posttreatment time points $[F(2,6)=9.8, p$ $<0.05]$. Figure 4 illustrates that, with increasing halothane concentrations, early arterial pressure responses to pinch, saline injection, and formalin (Phase 1) decreased in a graded manner. The highest halothane concentration $(2.1 \%)$ completely abolished these three early-onset responses, and ultimately led to respiratory depression. Although formalin injection produced an immediate reflexive withdrawal of the hindlimb, this response was momentary (less than $5 \mathrm{sec}$ ), and no behavior was observed for the duration of the experiment. After a quiescent interphase (duration of 15 min), only lightly anesthetized animals exhibited a second (Phase 2) formalin-associated response. In contrast, halothane concentrations as low as $0.9 \%$ completely abolished Phase 2. Compared to unanesthetized animals (Fig. 4), the Phase 2 pressor responses in lightly anesthetized animals was delayed; ANOVA revealed a Time $\times$ Group interaction $[F(45,405)=$ $1.43, p<0.01]$.

\section{Contribution of ongoing peripheral nerve activity}

To test the contribution of ongoing peripheral nerve activity to the expression of the Phase 2 pressor, tachycardia, and flinching responses, we subcutaneously administered local anesthetic into the formalin-injected paw, 10 min after $2.5 \%$ or $10 \%$ formalin (i.e., after Phase 1 had subsided). The higher concentration of formalin was used because a recent report by Coderre et al. (1994) showed a greater contribution of inflammation to formalin behavior at higher formalin concentrations. To avoid possible systemic effects of lidocaine (Abrams and Yaksh, 1994), we used QX-314, a charged quaternary lidocaine derivative that does not readily diffuse across membranes. In addition, we injected QX-314 into the contralateral paw; this procedure controlled for systemic effects, as well as for the injection itself. As can be seen in Figure 5, the QX-314 injection procedure produced only a transient increase in blood pressure and heart rate, similar to that observed after restraint or saline injection.

The four QX-314 groups did not exhibit significant differences in resting blood pressure and heart rate (Table 1), restraintevoked pressor and tachycardia responses $(p>0.05)$, or formalin-evoked Phase 1 pressor responses $(p>0.05)$. As expected, $10 \%$ formalin produced greater Phase 1 tachycardia responses than did $2.5 \%$ formalin $[F(1,27)=6.6, p<0.05]$; Fig. 5). Most importantly, ipsilateral, but not contralateral, QX-314 completely blocked the Phase 2 behavioral, pressor $[F(1,27)=$ $51.2, p<0.001]$, and tachycardia $[F(1,26)=13.38, p<0.005]$ responses (Figs. 5, 6). At the end of the 70 min test session, none of the animals exhibited a reflex response to needle prick of the formalin-injected hindpaw, suggesting a sufficiently long duration of action for QX-314.

\section{Discussion}

In the present studies, we demonstrate that central sensitization (hyperexcitability) of dorsal horn neurons, produced by formalin-evoked Phase 1 input, is not sufficient to maintain Phase 2 cardiovascular responses and pain behavior. In agreement with Dickenson and Sullivan (1987b), we conclude that sustained peripheral nerve input is required for the expression of Phase 2. In addition, the present study is the first to assess persistent pain in the awake animal with cardiovascular measures; other studies of the awake animal have only reported transient cardiovascular pain responses (Ness and Gebhart, 1988; Meller et al., 1992; Khan et al., 1994). We conclude that formalin-evoked cardiovascular responses, in addition to behavior, provide a reliable correlate of pain in the awake, freely moving rat.

Compared to behavioral observation alone, the simultaneous measurement of cardiovascular responses provides a more rigorous and accurate assessment of formalin-evoked pain. Although other nonbehavioral measures of formalin pain, including activity of dorsal horn neurons (Dickenson and Sullivan, 1987a,b) or peripheral nerve axons (Puig and Sorkin, 1994) are also excellent quantitative measures of nociceptor activation, these methods cannot be used in the awake animal. Also, measurement of blood pressure and heart rate is simpler and less invasivc. With cardiovascular measurement, we avoided several of the most common criticisms of behavioral scoring techniques. First, reliable discrimination between different degrees of pain behavior using the weighted-scoring method (Dubuisson and Dennis, 1977; Coderre et al., 1993) has a subjective element; in contrast, cardiovascular measurement is automatically and objectively recorded. Second, magnitude differences between the 


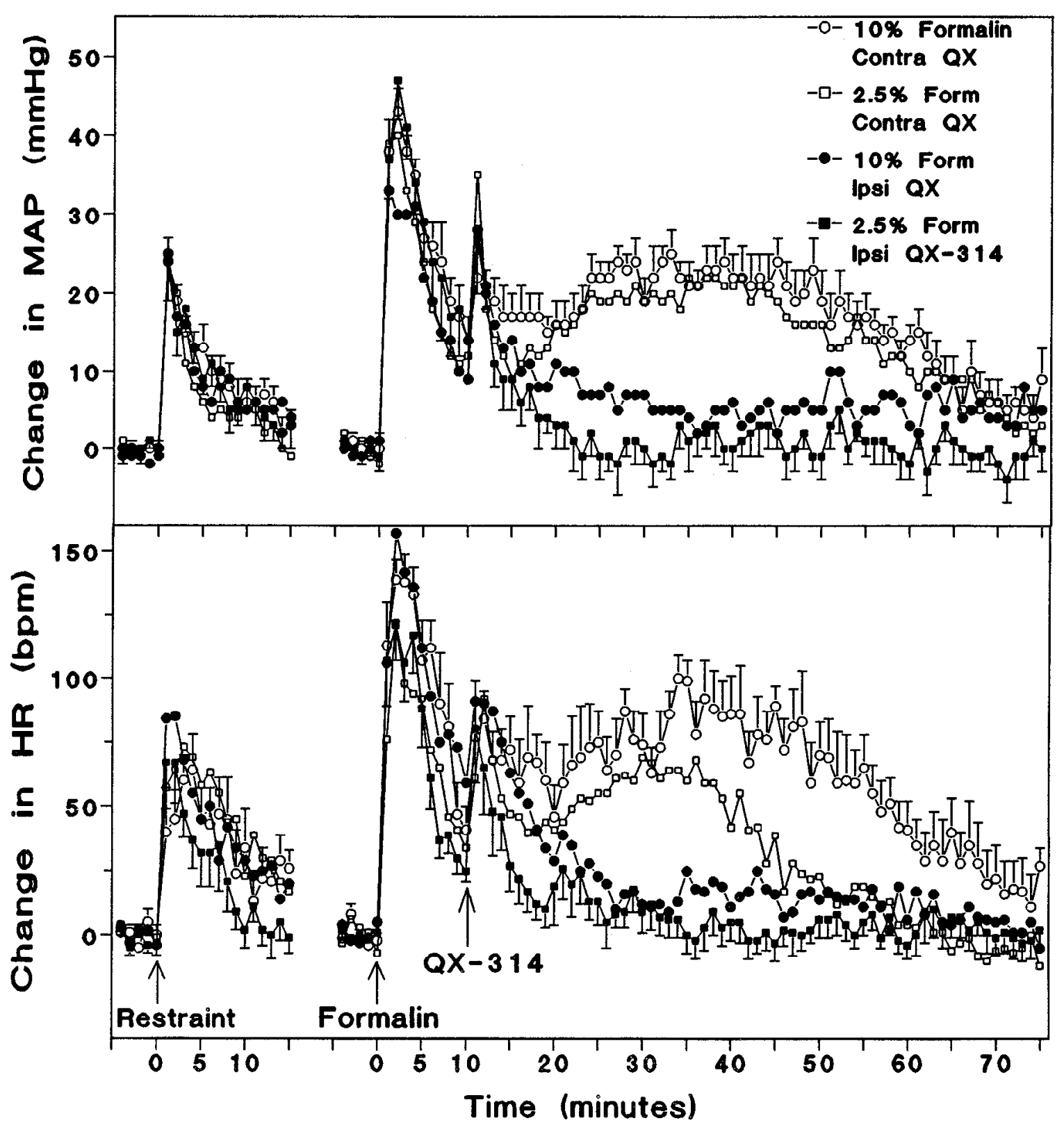

Figure 5. Local anesthesia blocks Phase 2 formalin-evoked cardiovascular responses. Sequential changes ( \pm SEM) in mean arterial pressure ( $M A P$, upper panel) and heart rate $(H R$, lower panel) following one minute of restraint and restraint plus intraplantar formalin injection. Ten minutes after formalin injection, $2 \%$ quaternary lidocaine was injected into the paw ipsilateral (Ipsi) or contralateral (Contra) to the formalin-injected paw.

ranks of the ordinal scale of the weighted-scoring method are unclear; the magnitude of cardiovascular changes is, however, a parametric measure. Third, competing behaviors may confound interpretation of results. For example, Wheeler-Aceto and Cowan (1993) reported that systemic naloxone increased formalininduced Phase 2 flinching behavior, but simultaneously reduced formalin-induced Phase 2 licking. Cardiovascular measurement should avoid this problem, and therefore could be used to reinvestigate treatments that yielded mixed experimental results. Fourth, behavioral measurement alone provides only a rough measure of arousal. Since we were able to refrain from testing until resting blood pressure and heart rate reached steady-state, cardiovascular recording minimizes potential interactions between nociceptive responses and arousal.

The similarities between the formalin-evoked cardiovascular behavioral and electrophysiological responses attest to the reliability of the paradigm. Furthermore, the duration and relative magnitude of Phase 1 and Phase 2 behavioral and cardiovascular responses were remarkably similar to those reported in electrophysiological studics (Dickenson and Sullivan, 1987b). Second, the magnitude of both behavioral (Coderre et al., 1993; Abbot and Franklin., 1995) and cardiovascular Phase 2 responses covaried with the concentration of the formalin. Third, quaternary lidocaine produced similar effects on the two measures. Fourth, flinching behavior was highly correlated with the pressor response and, in Charles River animals, the tachycardia response. Regardless of the vendor source of the animals, both flinching and cardiovascular responses exhibited the classical biphasic response profile. We found however, that Charles River animals exhibited slightly larger formalin-evoked flinching and tachy- 
Figure 6. Local anesthesia blocks Phase 2 formalin-evoked behavioral responses. Number of flinches $( \pm$ SEM) following intraplantar formalin injection $(2.5$ or $10.0 \%)$. Ten minutes after formalin injection, $2 \%$ quaternary lidocaine was injected into the paw ipsilateral (Ipsi) or contralateral (Contra) to the formalin-injected paw.

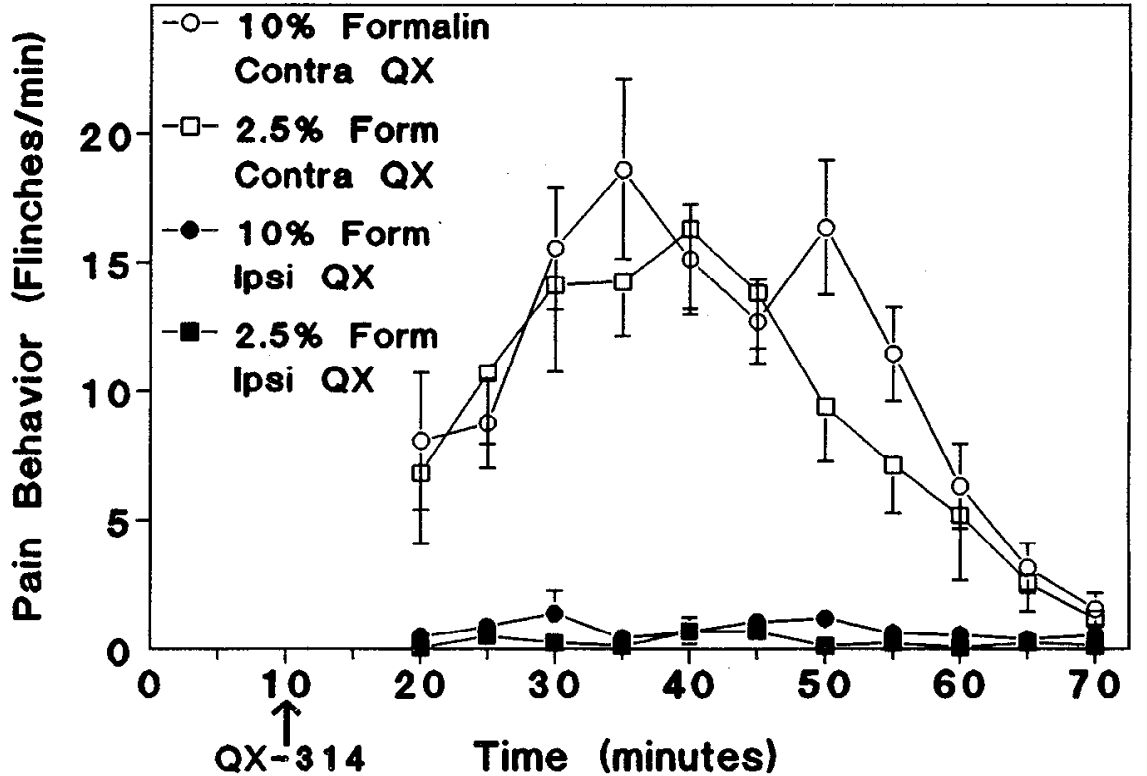

Phase 1 responses. It is possible that the higher halothane concentrations selectively disrupted central sensitization via actions at the spinal cord (Abram and Yaksh, 1993; O'Connor and Abram, 1995; but sce Herrero and Yardley, 1995) or at supraspinal sites (Farber et al., 1995).

\section{Local anesthesia}

The fact that post-Phase I injection of quaternary lidocaine (QX314) into the formalin-injected hindpaw completely blocked Phase 2 behavioral and cardiovascular responses argues for an important contribution of ongoing peripheral nerve activity to the expression of persistent pain. Since identical injections into the contralateral paw did not significantly change Phase 2 responses, we can rule out a systemic action of QX-314. A local effect of QX-314 could have influenced the central consequences of formalin injection in at least three ways: (1) a direct anesthetic action on peripheral nerves, (2) reduction of dorsal root reflexes that contribute to neurogenic inflammation or sympathetic discharge, and (3) a direct antiinflammatory action (Rimback et al., 1988).

In contrast to the current study, Coderre et al. (1990) reported that local anesthesia of the peripheral trigger site did not completely reduce formalin-evoked behavior. Three factors may explain the differences between these results. First, Coderre et al. (1990) evaluated pain behavior with the weighted-scoring method, whereas we counted flinching behaviors. Although the relative merit of these two methods is controversial, the cardiovascular data strongly support the behavioral flinching data. Second, since QX-314 is more hydrophilic than lidocaine (Butterworth and Strichartz, 1990), diffusion of QX-314 from the injection site is relatively restricted. Although Coderre et al. (1990) mentioned that their lidocaine block lasted for $1 \mathrm{hr}$, in a comparable study, Dickenson and Sullivan (1987b) found that intraplantar lidocaine only inhibited formalin-evoked dorsal horn neuronal activity for 10-20 min. Conceivably, the effects of lidocaine wore off before the end of Phase 2 in the Coderre et al., study, allowing a reemergence of behavior. Regardless of the difference between these results, we conclude that ongoing peripheral nerve activity during Phase 2 is required for the induction of Phase 2 formalin-evoked nociceptive responses, including be- 
havior and its cardiovascular correlates. Our results support the original findings of Dickenson and colleagues (Dickenson and Sullivan 1987b; Haley et al, 1990), and the recent findings of Dallel et al (1995), who found that post- but not pre-Phase 1 lidocaine blocked Phase 2 discharge of spinal cord neurons.

Recent clinical data indicate that stimuli associated with surgery or tissue injury can induce long-term hyperexcitability of spinal ncurons, which may contribute to postoperative or chronic pain conditions (McQuay, 1992; Dahl and Kehlet, 1993; Woolf and Chong, 1993). Although Phase 1 and Phase 2 pain in the formalin test may correspond to acute intraoperative and persistent postoperative pain, respectively, we did not selectively block Phase 1. Thus, our present results do not address the possibility that adequate pre- and intraoperative infiltration with local anesthetic block at the surgical site is sufficient to prevent the development of postoperative pain. On the other hand, the present studies indicate that Phase 2 nociceptive responses require peripheral nerve input, and are consistent with the suggestion of Woolf and Chong (1993) that a local anesthetic block applied only before and during the initial noxious stimulus (i.e., pre- and intraoperatively) is not sufficient to reduce/prevent postoperative pain. Rather, it is probably best to continue this treatment throughout the later periods of nociceptor activation associated with tissue injury and/or inflammation.

\section{References}

Abbott FV, Franklin KBJ, Westbrook RF (1995) The formalin test: scoring properties of the first and second phases of the pain response in rats. Pain 60:91-102.

Abdeen OA, Taylor BK, Youngblood KL, Printz MP (1995) Peripheral beta adrenergic blockade modifies airpuff startle-induced heart rate responses. J Pharmacol Exp Ther 272:282-289.

Abram SE, Kostreva DR, Hopp FA, Kampine JP (1983) Cardiovascular responses to noxious radiant heat in anesthetized cats. Am J Physiol 245(Reg Int Comp Physiol 14):R576-R580.

Abram SE, Yaksh TL (1993) Morphine, but not inhalation anesthesia, blocks post-injury facilitation. Anesthesiology 78:713-721.

Abram SE, Yaksh TL (1994) Systemic lidocaine blocks nerve injuryinduced hyperalgesia and nociceptor-driven spinal sensitization in the rat. Anesthesiology 80:383-391.

Altura BM, Altura BT, Carella A, Turlapaty PDMV, Weinberg J (1980) Vascular smooth muscle and general anesthetics. Fed Proc 39:15841591.

Butterworth JF, Strichartz GR (1990) Molecular mechanisms of local anesthesia: a review. Anesthesiology 72:711-734.

Coderre TJ, Melzack R (1992) The contribution of excitatory amino acids to central sensitization and persistent nociception after formalininduced tissue injury. J Neurosci 12:3665-3670.

Coderre TJ, Vaccarino AL, Melzack R (1990) Central nervous system plasticity in the tonic pain response to subcutaneous formalin injection. Brain Res 535:155-158.

Coderre TJ, Fundytus ME, McKenna JE, Dalal S, Melzack R (1993) The formalin test: a validation of the weighted-scores method of behavioral pain rating. Pain 54:43-50.

Coderre TJ, Yashpal K, Henry JL, Katz J (1994) Efficacy of pre-emptive anesthesia on nociceptive responses to formalin in rats: effects of peripheral inflammation and barbiturate/opioid pre-medications. Soc Neurosci Abstr 20:130.

Cohen DH, Obrist PA (1975) Interactions between behavior and the cardiovascular system. Circ Res 37:693-706.

Cook AJ, Woolf CJ, Wall PD, McMahon SB (1987) Dynamic receptive field plasticity in rat spinal cord dorsal horn following C-primary afferent inputs. Nature 325:151-153.

Dahl JB, Kehlet H (1993) The value of pre-emptive analgesia in the treatment of postoperative pain. Br J Anaesth 70:434-439.

Dallel R, Raboisson P, Clavelou P, Saade M, Woda A (1995) Evidence for a peripheral origin of the tonic nociceptive response to subcutaneous formalin. Pain 61:11-16.

Dickenson AH, Sullivan AF (1987a) Subcutaneous formalin-induced activity of dorsal horn neurones in the rat: different responses to an intrathecal opiate administered pre- or post-formalin. Pain 30:339348.

Dickenson AH, Sullivan AF (1987b) Peripheral origins and central modulation of subcutaneous formalin-induced activity of rat dorsal horn neurones. Neurosci Lett 83:207-211.

Dray A, Urban L, Dickenson A (1994) Pharmacology of chronic pain. Trends Pharmacol Sci 15:190-197.

Dubuisson D, Dennis SG (1977) The formalin test: a quantitative study of the analgesic effects of morphine, meperidine and brainstem stimulation in rats and cats. Pain 4:161-1/4.

Farber NE, Samso E, Kampine JP, Schmeling WT (1995) The effects of halothane on cardiovascular responses in the neuraxis of cats. Anesthesiology 82:153-165.

Haley JE, Sullivan AF, Dickenson AH (1990) Evidence for spinal $\mathrm{N}$-methyl-D-aspartate receptor involvement in prolonged chemical nociception in the rat. Brain Res 518:218-226.

Herrero JF, Headley PM (1995) Sensitization of spinal neurons by nonnoxious stimuli in the awake but not anesthetized state. Anesthesiology 82:267-275.

Hilton SM, Redfern WS (1986) A search for brainstem cell groups integrating the defense reaction in the rat. J Physiol (Lond) 378:213228.

Ishizawa Y, Dohi S (1993) Halothane concentrations required to block the cardiovascular responses to incision (MAC CVR) in infants and children. Can J Anaesth 40:18-23.

Khan IM, Taylor P, Yaksh TL (1994) Cardiovascular and behavioral responses to nicotinic agents administered intrathecally. J Pharmacol Exp Ther 270:150-158.

Lovick TA (1993) Integrated activity of cardiovascular and pain regulatory systems: role in adaptive behavioral responses. Prog Neurobiol 40:631-644.

Martner J, Biber B (1982) Anaesthesia and cardiovascular regulation. Acta Anaesth Scand Suppl 76:20-31.

McQuay HJ (1992) Pre-emptive analgesia. Br J Anaesth 69:1-3.

Meller ST, Lewis SJ, Brody MJ, Gebhart GF (1992) Age, strain and anesthetic dependent differences in the nociceptive responses produced by i.v. 5-HT in the rat. Brain Res 587:88-94.

Murray CW, Cowan A, Larson A (1991) Neurokinin and NMDA antagonists (but not a kainate antagonist) are antinociceptive in the mouse formalin model. Pain 44:179-185.

Nagasaka H, Yaksh T (1990) Pharmacology of intrathecal adrenergic agonists: cardiovascular and nociceptive reflexes in halothane-anesthetized rats. Anesthesiology 73:1198-1207.

Ness TJ, Gebhart GF (1988) Colorectal distension as a noxious visceral stimulus: physiologic and pharmacologic characterization of pseudoaffective reflexes in the rat. Brain Res 450:153-169.

O'Connor TC, Abram SE (1995) Inhibition of nociception-induced spinal sensitization by anesthetic agents. Anesthesiology 82:259-266.

Olsen UB, Lund A (1991) Inhibition by glutamate antagonists, MK801 and NBQX, of cutaneo-cardiovascular pain reflex in rats. Eur J Pharmacol 203:133-135.

Puig S, Sorkin LS (1994) Subcutaneous formalin evoked activity in single fibers of rat sural nerve. Soc Neurosci Abstr 20:760.

Randich A, Maixner W (1984) Interactions between cardiovascular and pain regulatory systems. Neurosci Biobehav Rev 8:343-367.

Rimback G, Cassuto J, Wallin G, Westlander G (1988) Inhibition of peritonitis by amine local anesthetics. Anesthesiology 69:881-886.

Roizen MF, Horrigan RW, Frazer BM (1981) Anesthetic doses blocking adrenergic (stress) and cardiovascular responses to incision-MAC BAR. Anesthesiology 54:390-398.

Seagard JL, Hopp FA, Bosnjak ZJ, Elegbe EO, Kampine JP (1983) Extent and mechanism of halothane sensitization of the carotid sinus baroreceptors. Anesthesiology 58:432-437.

Sokolov EN (1963) Perception and the conditioned reflex. Oxford: Plenum.

Taylor BK, Holloway DH, Printz MP (1994) A unique cholinergic deficit in the spontaneously hypertensive rat: physostigmine reveals a bradycardia response associated with sensory stimulation. J Pharmacol Exp Ther 268:1081-1090.

Tjolsen A, Berge O-G, Hunskaar S, Rosland JH, Hole K (1992) The formalin test: an evaluation of the method. Pain 51:5-17.

West WL, Yeomans DC, Proudfit HK (1993) The function of noradrenergic neurons in mediating antinociception induced by electrical stimulation of the locus coeruleus in two different sources of Sprague-Dawley rats. Brain Res 626:127-135. 
Wheeler-Aceto H, Cowan A (1991) Standardization of the rat paw formalin test for the evaluation of analgesics. Psychopharmacology 104:35-44.

Wheeler-Aceto H, Cowan A (1993) Naloxone causes apparent antinociception and pronociception simultaneously in the rat paw formalin test. Eur J Pharmacol 236;193-199.

Woolf CJ (1983) Evidence for a central component of post-injury pain hypersensitivity. Nature 308:686-688.

Woolf CJ, Chong M-S (1993) Preemptive analgesia-treating postop- erative pain by preventing the establishment of central sensitization. Anesth Analg 77:362-379

Yamamoto T, Yaksh TL (1991) Stereospecific effects of a nonpeptidic NK1 selective antagonist, CP,96-345: antinociception in the absence of motor dysfunction. Life Sci 49:1955-1963.

Yamamoto T, Taksh TL (1992) Comparison of the antinociceptive effects of pre- and posttreatment with intrathecal morphine and MK801, an NMDA antagonist, on the formalin test in the rat. Anesthesiology 77:757-763. 